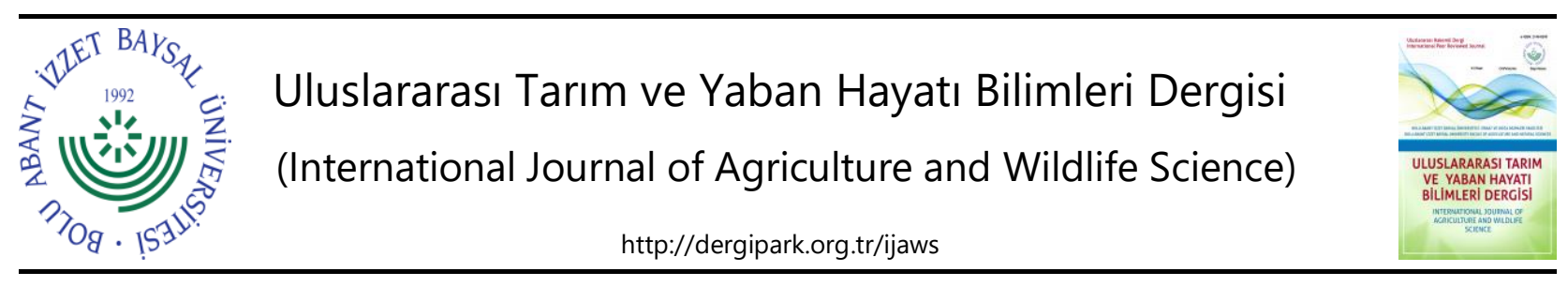

Araştırma Makalesi

\title{
Tarımsal Uygulamalarda ANSYS Kullanımı: Tarım Arabası Aksı Modellenmesi ve Analizi Örneği
}

\author{
İsmail Terzi * (D), Mehmet Metin Özgüven (D), Ziya Altaş \\ Gaziosmanpaşa Üniversitesi Ziraat Fakültesi Biyosistem Mühendisliği Bölümü, Tokat \\ Geliş tarihi (Received): 06.05.2021 Kabul tarihi (Accepted): 21.09.2021
}

\begin{abstract}
Anahtar kelimeler:
ANSYS, tarım, tarım

arabası, aks, mukavemet
\end{abstract}

\begin{abstract}
*Sorumlu yazar
\end{abstract}
iso_di_@hotmail.com

\begin{abstract}
Özet. ANSYS, araştırma ve geliştirme uygulamalarında analizlerin ve simülasyonların yapılabildiği bilgisayar destekli mühendislik programıdır. Mekanik, yapısal analiz, hesaplamalı akışkanlar dinamiği ve ISı transferi gibi farklı hesaplamalı uygulamalarda ANSYS programı kullanılmaktadır. Bu çalışmada, ANSYS paket yazılım programı genel hatlarıyla açıklanmaya çalışılmış, ANSYS'in tarımdaki uygulamalarına yönelik bazı çalışmalara yer verilmiş ve tarım arabası aksının modellemesi ve analizi yapılmıştır. Tarım arabalarında dikdörtgen kesitli ve dairesel kesitli akslar kullanılmaktadır. Bu nedenle çalışmada hem dikdörtgen kesitli hem de dairesel kesitli aks üzerinde statik bir analiz yapılmış ve her iki akstan elde edilen sonuçlar karşılaştırılmıştır. Bulgularda her iki aksa ait eşdeğer gerilim, eşdeğer elastik gerilim, toplam deformasyon ve güvenlik faktörü analizleri elde edilmiştir. SolidWorks programı kullanılarak aksların katı modellemesi 3 boyutlu olacak şekilde oluşturulduktan sonra ANSYS Workbench kullanılarak modelleme sonrası aksların çalışma şartları gerçeğe uygun olacak şekilde simüle edilmiş ve akslar üzerinde oluşan gerilme dağılımları incelenerek gerilmelere ait gerekli analizler yapılmıştır. Sonuç olarak ise, maksimum eşdeğer gerilim, dairesel kesitli aksta $15.892 \mathrm{MPa}$, dikdörtgen kesitli aksta ise $12.026 \mathrm{MPa}^{\prime}$ dır. Maksimum eşdeğer elastik gerilim, dairesel kesitli aksta $7.9463 \mathrm{e}-5 \mathrm{~mm}$ $\mathrm{mm}^{-1}$, dikdötrgen kesitli aksta ise $6.8408 \mathrm{e}-5 \mathrm{~mm} \mathrm{~mm}^{-1}$ dir. Toplam deformasyon dairesel kesitli aksta $0.077806 \mathrm{~mm}$, dikdörtgen kesitli aksta ise $0.053021 \mathrm{~mm}$ 'dir. Güvenlik faktörü ise her iki aksta da eşit olarak bulunmuştur.
\end{abstract}

\section{Use of ANSYS in Agricultural Applications: Trailer Axle Modeling and Analysis Example}

\section{Keywords:}

ANSYS, agriculture, trailer, axle, strength

\begin{abstract}
ANSYS is a computer-aided engineering program in which analysis and simulations can be performed in research and development applications. ANSYS program is used in different computational applications such as mechanics, structural analysis, computational fluid dynamics and heat transfer. In this study, the ANSYS software program was tried to be explained in general terms, some studies on the applications of ANSYS in agriculture were included, and the modeling and analysis of the tractor trailer axle was made. Rectangular and circular cross-section axles are used in tractor trailers. For this reason, in study, a static analysis was made on both the rectangular and circular crosssection axes and the results obtained from both axes were compared. In the findings, equivalent stress, equivalent elastic stress, total deformation and factor of safety analysis results were obtained for both axes. After the solid modeling of the axles was created in 3 dimensions using the SolidWorks program, the working conditions of the axles after modeling were simulated in accordance with the reality by using the ANSYS Workbench, and the necessary analyzes of the stresses were made by examining the stress distributions on the axles. As a result, the maximum equivalent stress $15.892 \mathrm{MPa}$ on the circular cross-section axis and $12.026 \mathrm{MPa}$ on the rectangular cross-section axis. The maximum equivqlent elastic stress is $7.9463 \mathrm{e}-5 \mathrm{~mm} \mathrm{~mm}^{-1}$ in circular cross-section axle and $6.8408 \mathrm{e}-5 \mathrm{~mm} \mathrm{~mm}^{-1}$ in rectangular cross-section axle. Total deformation is $0.077806 \mathrm{~mm}$ at the circular cross-section axis and 0.053021 $\mathrm{mm}$ at the rectangular cross-section axis. The safety factor was found to be equal in both axes.
\end{abstract}




\section{GíRiş}

ANSYS, fiziğin bütün disiplinlerinin birbirleriyle olan etkileşimini simüle etmek amacıyla; mukavemet, titreşim, akışkanlar mekaniği, ısı transferi ve elektromanyetik alanlarında uygulaması yapılabilen ve endüstride geniş kullanım alanı olan bilgisayar destekli mühendislik programıdır (Souza ve ark., 2018).

ANSYS sonlu eleman programı, ürünlerin daha prototipleri üretilmeden sanal ortamda test edilmelerini sağlamaktadır. Prototip üretiminin, simülasyon yöntemine göre daha maliyetli ve fazla zaman gerektirmesinden dolayı çalışmalarda bilgisayar destekli mühendislik yöntemi tercih edilmektedir. ANSYS yazııımı hem dışardan CAD (Computer Aided Design) datalarını alabilirken hem de içindeki işlem olanakları ile geometri oluşturulmasına imkan verebilmektedir. Dolayısıyla ürünün kaliteli ve en az maliyetli olabilmesi için gerekli dizayn koşulları ANSYS sayesinde bulunabilmektedir (Kibar ve Öztürk, 2012).

ANSYS'de bir analiz genel olarak 3 aşamadan oluşmaktadır.

\section{Preprocessor (1.aşama)}

Modelin oluşturulması veya hazır modelin ANSYS'e aktarılması ile başlayarak modele malzeme ataması (elastisite modülü, birim ağılık, poisson oranı vb.) yapılır. Daha sonra Şekil 1'de gösterildiği gibi model, sonlu elamanlara bölünerek ağ örgüsü (mesh) yapılır. Buradaki önemli unsur analiz biçimine ve geometriye göre doğru eleman şeklinin tespit edilmesidir. Bir elemanı belirleyen özellikler; elemanın serbestlik derecesi, elemanın şekli, elemanın boyutu ve varsayılan deformasyon biçimidir.

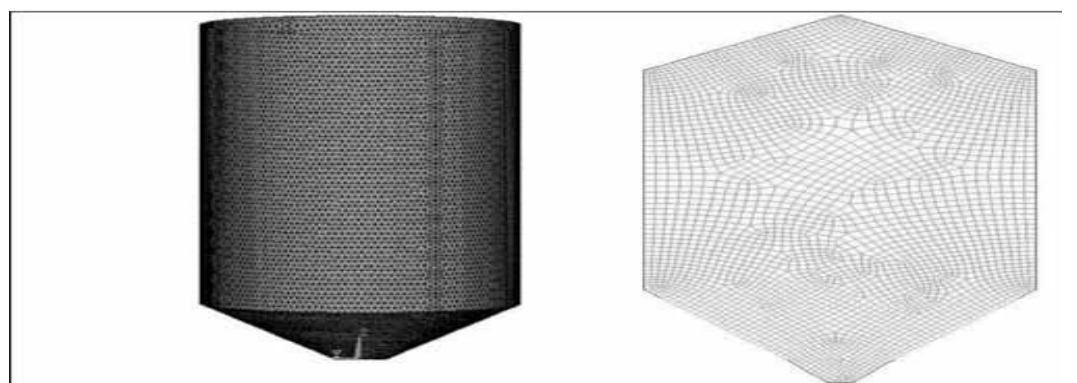

Şekil 1. Tarımsal silolara ilişkin ağ örgü (mesh) şekilleri (Kibar, 2011).

Figure 1. Mesh shapes for agricultural silos.

\section{Solution (2.aşama)}

ANSYS'te yapılması istenen analizin tipi seçilir. Burada ANSYS cisimlerin statik, dinamik, termal, harmonik, elektromanyetik gibi birçok alanda analiz ve dizayn optimizasyonu işlemlerini yapabilmektedir.

\section{Postprocessor (3.aşama)}

Sonuçların okunduğu ve yorumlandığı aşamadır. Sonuç gözlemleri burada birçok şekilde yapılabilmektedir. Sonuçlar çizelge şeklinde, istenilen özelliklerin gerilme dağılımını gösteren çizimler şeklinde veya deforme olmuş cisimler şeklinde gösterilebilmektedir. Bunun yanında modelin yük altındaki davranışı animasyon yardımı ile de gösterilebilmektedir.

ANSYS programında, tasarımı yapılacak olan ürünün yapısal ve işlevsel elemanlarının çalışma koşullarının incelenmesinde modelleme ve simülasyon teknikleri kullanılmaktadır. Bir sistemin somut halinin bilgisayar ortamında bir örneğinin yapılarak benzetme yoluyla gösterimine modelleme denir. Simülasyon (benzetim) ise; sistemin modelini tasarlama aşaması ve sistemin işlevini anlamayı veya farklı stratejiler geliştirmeyi sağlayan, model üzerinde denemeler yapan, zamana bağlı olarak bu sistemin modelini tarif eden matematiksel bir yöntemdir.

ANSYS programında kullanılan modelleme ve simülasyon, hemen hemen her türlü sisteme uygulanabilmekte ve uygulandığı sistemin sorunlarının çözümünü kolaylaştırmaktadır. Tarımda bu tekniklerin uygulama alanları toprak işlemeden ürün hasadına kadar birçok uygulamada, sistem performansının artırımasına, üretim yöntemlerinin geliştirilmesine, sisteme ait problemlerin daha rahat görülmesine ve çözüm yollarının bulunmasına katkı sağlamaktadır. Ayrıca, belirlenen şartlar altında yapılan üretimlerin karşılaşıııımasında, elde edilecek üretimin tahmininde bulunulmasında, üretim yapılırken hangi faktörlerin etkili olup olmadığının belirlenmesinde ve sisteme olumsuz etkisi olan darboğazların gözlemlenmesinde önemli rol oynamaktadır (Terzi ve ark., 2019).

Birçok sonlu eleman içerisinde ANSYS en eski ve en ileri kullanılan yazılımlardan birisidir. Havacılık, otomotiv, elektronik, enerji; yenilenebilir enerji kaynaklarından olan rüzgar enerjisi (Blaabjerg ve ark., 2017; Boldea ve ark., 2017), büyük rüzgar türbinleri ve rüzgar santralleri için güç elektroniğinin ve kontrollerinin nasıl sağlandığı (Ma ve 
ark., 2017), güneş enerjisi (Kim ve ark., 2017) turbo makineler, inşaat ve sağlık gibi birçok endüstri kolunda çok geniş kullanım alanı olan ANSYS, tarımda; sera koşullarının modellenmesinde (Atiş, 2011; Franco ve ark., 2011), silolarda statik koşulların belirlenmesinde, silo tasarımında (Gallego ve ark., 2010; Kibar ve Öztürk, 2012), hayvan barınaklarında ve kümeslerde tasarım ve ısı transferi modelinin yapılmasında, doğal ve mekanik havalandırma sistemlerinde (Franco ve ark., 2011), depolanmışürün teknolojisinde, depo ürünlerinin depoya uyguladığı basıncın belirlenmesinde, depo içi mikroklima şartlarının tespitinde, meyvelerin işlenmesi ve taşınmasında olası zararları önceden tahmin edebilmek amacıyla simülasyonların yapımında (Thorpe, 2008; Delele ve ark., 2012; Akdemir, 2016), tarımsal sulamanın modellenmesi ve su kanallarııı tasarımında, tarım ürünlerinin özelliklerinin (sertlik, uzunluk, çap vs.) tahribatsız bir şekilde belirlenmesinde, tarım alet ve makinelerinin tasarım ve hesaplama işlemlerinin yapılmasında (Mollazade ve ark., 2010; Topakci ve ark., 2010; Yu ve ark., 2017; Selvi and Kabas, 2018; Şahin ve ark., 2018; Meng ve ark., 2019; Celik ve ark., 2020) vb. gibi birçok farklı uygulamada ANSYS kullanılmaktadır.

ANSYS programında, traktör ön aksının modellemesi ve tasarımı yapılarak, optimize edilmiş modeldeki sapma ve gerilimin mevcut modeldeki sapma ve gerilme ile karşılaştırılması yapılabilmektedir (Saravanan ve ark., 2017). Farklı toprak koşullarında kullanılabilecek en uygun toprak işleme alet ve makinesinin belirlenmesi (Çelik ve ark. 2007), en kötü yükleme şartları altında toprak işleme ekipmanlarının detaylı bir yapısal analizi, dinamik analizi, şekilsel analizi, harmonik analizi ve geçici analizi sonlu elemanlar paket yazilımı olan ANSYS Workbench kullanılarak incelenebilmektedir (Reddy ve ark., 2017). Rijid dinamik simülasyon modellemesi ile tarım arabasının piston bağlantı noktalarının yük altındaki yorulma analizleri (Aldağ, 2015), yük arabası aksının CAD modelini ANSYS'te hazırlayarak sonlu eleman analizi yapılıp, yük arabasında toplam deformasyon, basınç ve gerilme dağılımı (Sharma and Kumar 2016) ile tarım arabası şasisinin statik ve titreşim analizi optimizasyonu gerçekleştirilip, modeller üzerinde toplam deformasyon ve maksimum gerilme hesaplamaları yapılabilmektedir (Azade 2018). Kurutma sistemlerinde, ANSYS programı kullanılarak tasarlanan kurutma odası modellerinin ve geleneksel kurutma odası modellerinin sıcaklık dağılımlarını ve akım çizgilerini ortaya çıkarma işlemleri (Akman ve ark., 2018), silo sistemlerinde, çeşitli deneylerle normal basınç ve deneysel basınçların karşılaştırılması yapılabilmektedir (Gallego ve ark., 2015). Hasat makinelerinde, hasat esnasında hasat makinesi kolu ile hasat edilen ürünün birbirlerine olan etkisinin sonlu elemanlar analizine dayalı olarak değerlendirilebilmektedir (Souza ve ark., 2018). Budama işlemlerinde, dairesel testere kesme bıçağının ve budanacak ağaç dalıın eş değer gerilim dağııımının ve bu çalışma koşulu altında testere bıçağı üzerindeki etkili gerilim dağılımlarının dinamik değişikliklerinin diyagramı gösterilerek gerilmelerin çalışma koşullarına uygun olup olmadığı ANSYS programında ortaya çıkarılabilmektedir (Meng ve ark., 2019).

Bu çalışmada tarım arabası aksının ANSYS sonlu elemanlar yazılım programı kullanılarak, stres ve deformasyon analizleri yapılmıştır. Çalışmada hem dikdörtgen kesitli aks hem de dairesel kesitli aks kullanılarak, elde edilen analiz sonuçları karşılaştırılmıştır.

\section{MATERYAL VE METOT}

Tarım arabası; ek maliyeti ve araç masraflarını ortadan kaldırması, bakım masraflarııı az olması, uzun yıllar kullanılabilmesi, çok amaçlı olması, yükleme ve boşaltma işleminin kolay olması gibi birçok özelliğinden dolayı tarımsal alan taşımacılığında hem üreticilerin hem de firmaların çok tercih ettiği bir araçtır.

SolidWorks programında modellemeleri çizilen, Şekil 2'de gösterilen ve tarım arabalarında kullanılan dikdörtgen kesitli ve dairesel kesitli akslar seçilmiş, analizlerin yapılması için boyutları Çizelge $1^{\prime}$ de verilen bir tarım arabası kullanılmıştır.

Çizelge 1. Modellemesi yapılan 10 ton yükleme kapasiteli ve 4 tekerlekli tarım arabası özellikleri. Table 1. Modeled 10 ton loading capacity and 4 wheel trailer features.

\begin{tabular}{llcc}
\hline Sıra No. & & Tarım arabası özellikleri & \\
\hline 1 & Uzunluğu & & 4880 \\
2 & Genişliği & $\mathrm{mm}$ & 2290 \\
3 & Yüksekliği & & 1780 \\
4 & Aksın çapı-uzunluğu & & $120-2060$ \\
\hline 5 & Taşıma kapasitesi & KN & 70 \\
6 & Yüksüz ağırlık & & 30 \\
7 & Brüt yük ağırlığı & & 100 \\
\hline
\end{tabular}


Aksı etkileyen yükler ve bu yüklerin yerleri model içerisinde gösterilmiştir. Aksların SolidWorks programı kullanılarak boyutlara göre modellemesi yapılmıştır. Daha sonra akslar ANSYS programına aktarılarak burada analiz (meshleme (ağ) işlemi, yükleme diyagramı, Von- misses gerilimi analizi, eş değer elastik gerilim analizi, toplam deformasyon ve güvenlik faktör analizi) işlemlerine geçilmiştir.

\section{Model Oluşturma}

Tarım arabalarında dikdörtgen ve dairesel kesitli akslar kullanılmaktadır. Şekil 2' de dikdörtgen ve dairesel kesitli aksların SolidWorks programında çizilen modellemeleri ve teknik resimleri gösterilmektedir.

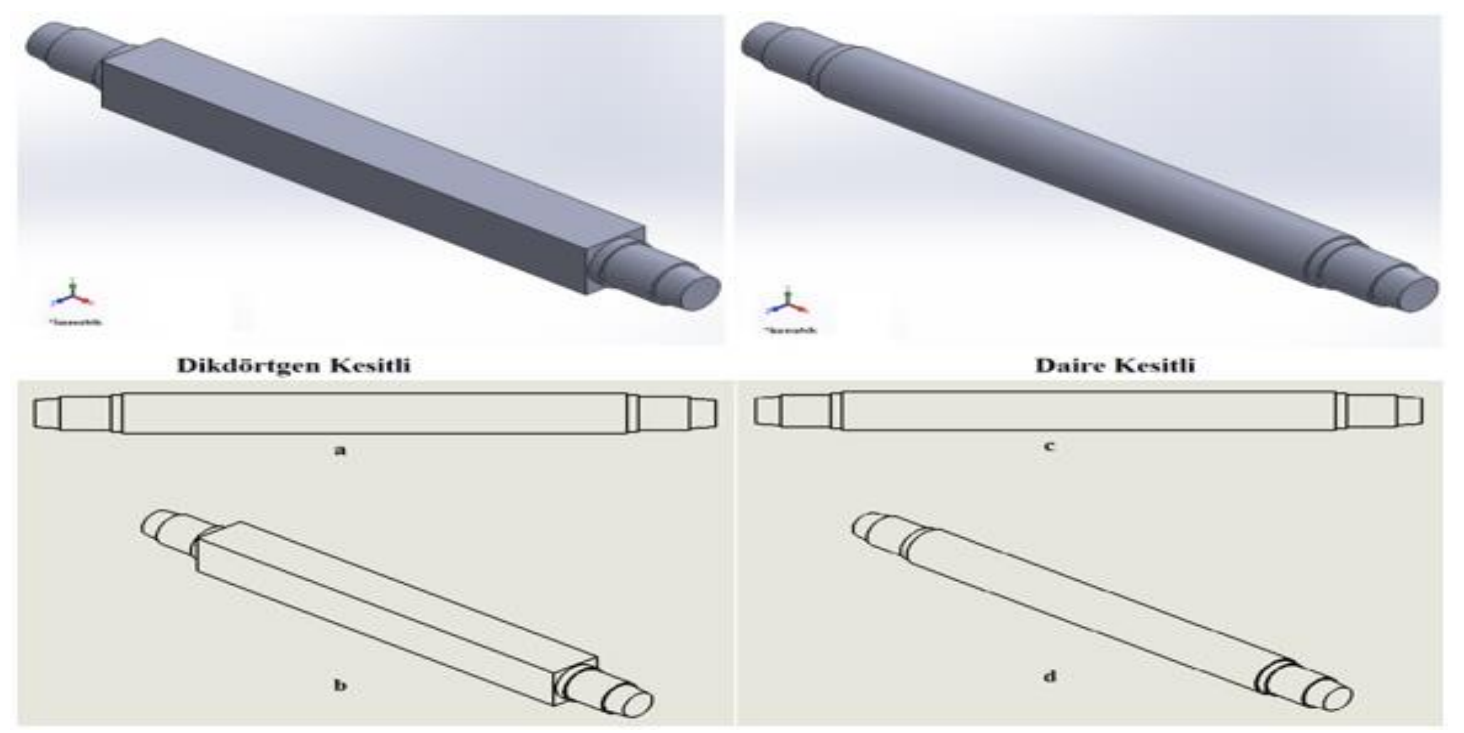

Şekil 2. Dikdörtgen ve dairesel kesitli aks modelleri ve teknik resimleri (a: Dikdörtgen kesit ön görünüş, b: Dikdörtgen kesit izometrik görünüş, c: Dairesel kesit ön görünüş, d: Dairesel kesit izometrik görünüş).

Figure 2. Rectangular and circular section axle models and technical drawings(a: Rectangular section front view, b: Rectangular section isometric view, c: Circular section front view, $d$ : Circular section isometric appearance).

Tarım arabası aksı için yapısal çelik malzeme kullanılmıştır. Çizelge 2'de bu malzemeye ait özellikler gösterilmektedir.

Çizelge 2. Aks için kullanılan malzeme özellikleri.

Table 2. Material properties used for axle.

\begin{tabular}{ll}
\hline Malzeme & Yapısal çelik \\
\hline Elastikiyet kat sayısı & $2, \mathrm{e}+005 \mathrm{Mpa}$ \\
Paisson oranı & 0.3 \\
Yoğunluk & $7,85 \mathrm{e}-006 \mathrm{~kg} \mathrm{~mm}^{-3}$ \\
Gerilme dayanım mukavemeti & $250 \mathrm{Mpa}$ \\
Son gerilme mukavemeti & $460 \mathrm{Mpa}$ \\
\hline
\end{tabular}

Çizelge 1'de özellikleri verilen tarım arabası ve Şekil 2'de gösterilen aks parçaları SolidWorks katı model yazıımı kullanılarak 3 boyutlu olacak şekilde modellenmiştir. Çalışmada ANSYS Workbench kullanılarak modelleme sonrası aksların çalışma şartları gerçeğe uygun olacak şekilde simüle edilmiş, akslar üzerinde oluşan gerilme dağılımları incelenmeye çalışılmıştır. Modellemesi yapılan aksların ANSYS yazılımı ile simülasyon ortamında farklı çalışma şartları ve yüklenme senaryoları incelenmiştir. Gerilme analizleri uygulanırken, gerçek çalışma ortamlarına maksimum düzeyde yaklaşabilmek için akslar bütün boyutu ile modellenmiştir. Elde edilen gerilme analizlerine ait sonuçlar şekilsel olarak, ANSYS Workbench'in orijinal çıktıları şeklinde sunulmuştur. Simülasyonu yapılan akslar çalışma ortamları için değerlendirilmeye alınmıştır.

\section{Ağ Oluşturma (Meshing)}

Modellemenin bir sonraki aşaması, oluşturulan modelin meshleme (ağ) işlemlerinin yapılmasıdır. Mesh yapmadan önce ilk olarak yapılacak olan analizin türü seçilmektedir. Daha sonra metot kısmından element tipi belirlenmektedir. Yani uygulanacak mesh yapıları (automatic, tetrahedrons, hex dominant, sweep, multizone, cartezian vb.) seçilmektedir. Mesh yoğunluğu artırılıp azaltılabilmektedir. Geometrinin tümüne olduğu gibi geometri üzerinde yüzey, çizgi ve nokta seçilerek belli bölgeleri farklı yoğunluklarda da mesh yapılabilmektedir. 
Çalışmada tasarlanan modellerin karmaşık bir yapı göstermemesinden dolayı otomatik meshleme uygulanmış ve mekanik analiz türü seçilmiştir. Meshleme için aşağıdaki parametreler (düğüm sayısı ve eleman sayısı) kullanılmıştır. Şekil 3 ve Şekil 4'te meshlemeler gösterilmiştir. Sonlu elemanlar yöntemi yaklaşık çözümler üreten bir yöntemdir. Eleman sayısı arttırılarak, eleman tipi değiştirilerek, mesh üretim metodu değiştirilerek veya mesh üzerinde manuel olarak oynanarak çözüm tekrarlanabilmekte ve tasarımı planlanan yapıya uygun mesh şekillerinin seçilmesiyle gerçeğe yakın sonuçlar elde edilebilmektedir.

\section{Dikdörtgen kesitli aks için;}

Düğüm Sayısı: 2728

Eleman SayısI: 1464
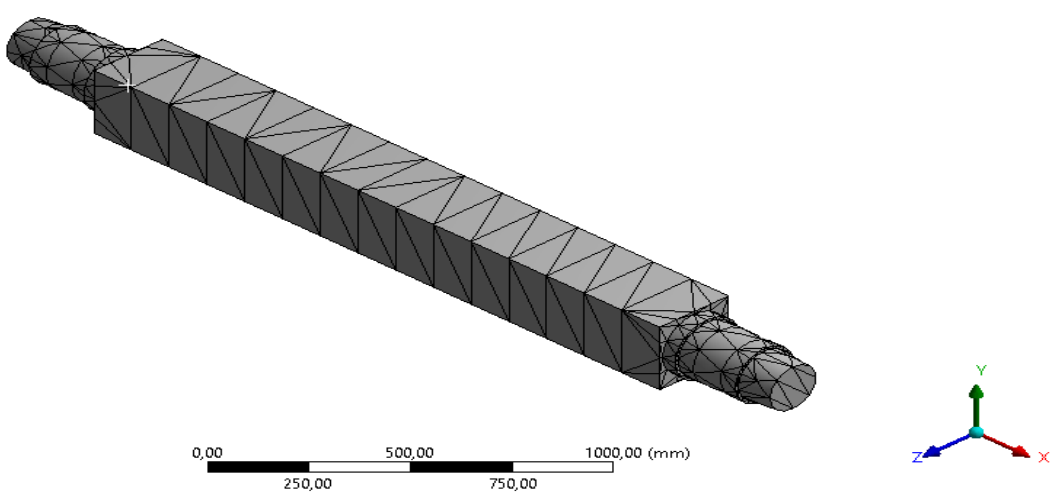

Şekil 3. Dikdörtgen kesitli aks meshlemesi.

Figure 3. Meshing of rectangular axle.

Dairesel kesitli aks için;

Düğüm Sayısı: 3426

Eleman Sayısı: 1856

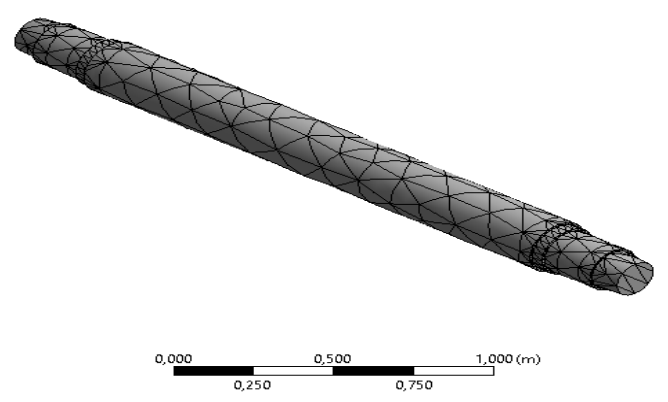

Şekil 4. Dairesel kesitli aks meshlemesi.

Figure 4. Meshing of circular cross section axle.

\section{Tarım Arabası Aksı Yük Diyagramı}

Tarım arabası aksının yük diyagramı Şekil 5 'te gösterilmiştir.

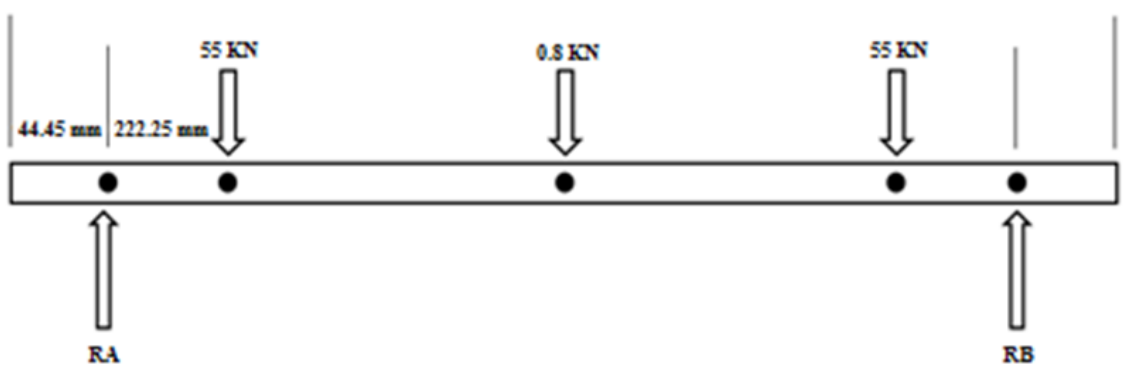

Şekil 5.Yük diyagramı

Figure 5. Load diagram 


$$
\begin{aligned}
& \text { A: Static Structural } \\
& \text { Static Structural } \\
& \text { Time: 1, s } \\
& \text { 9.09.2021 13:31 } \\
& \text { A Fixed Support } \\
& \text { B Force: } 55000 \mathrm{~N} \\
& \text { C Force 2: } 800, \mathrm{~N} \\
& \text { D Force 3: } 55000 \mathrm{~N}
\end{aligned}
$$
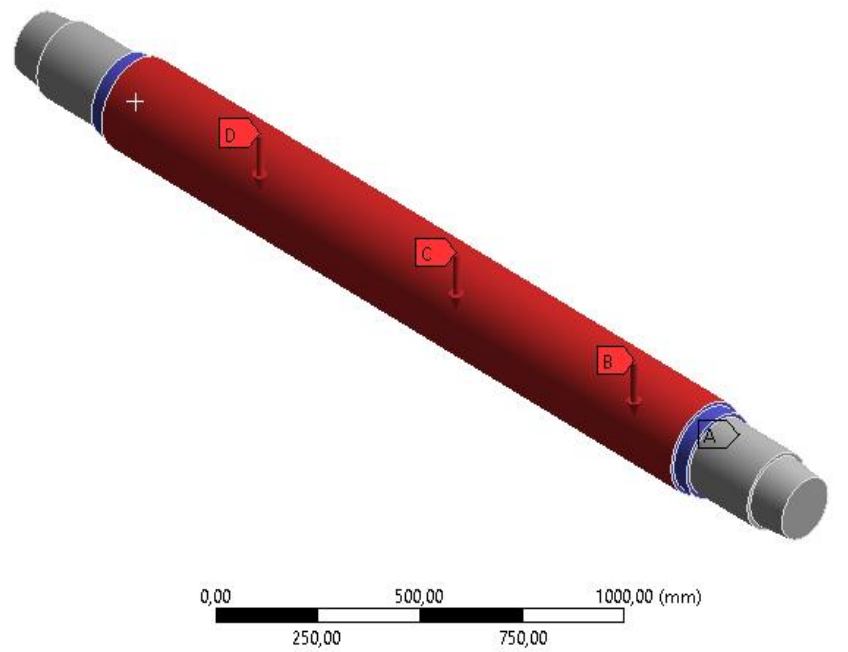

Şekil 6. Dairesel kesitli tarım arabası aksının yük şeması.

Figure 6. Load diagram of circular section trailer axle.

Şekil 6'da gösterildiği gibi mavi renkle gösterilen A noktası sabit destek noktasıdır. Kırmızı renkle gösterilen yüzeyde ise B ve D noktalarına $55000 \mathrm{~N}$ (5500 kg) yük, C noktasına $800 \mathrm{~N}(80 \mathrm{~kg}$ ) yük uygulanmaktadır.
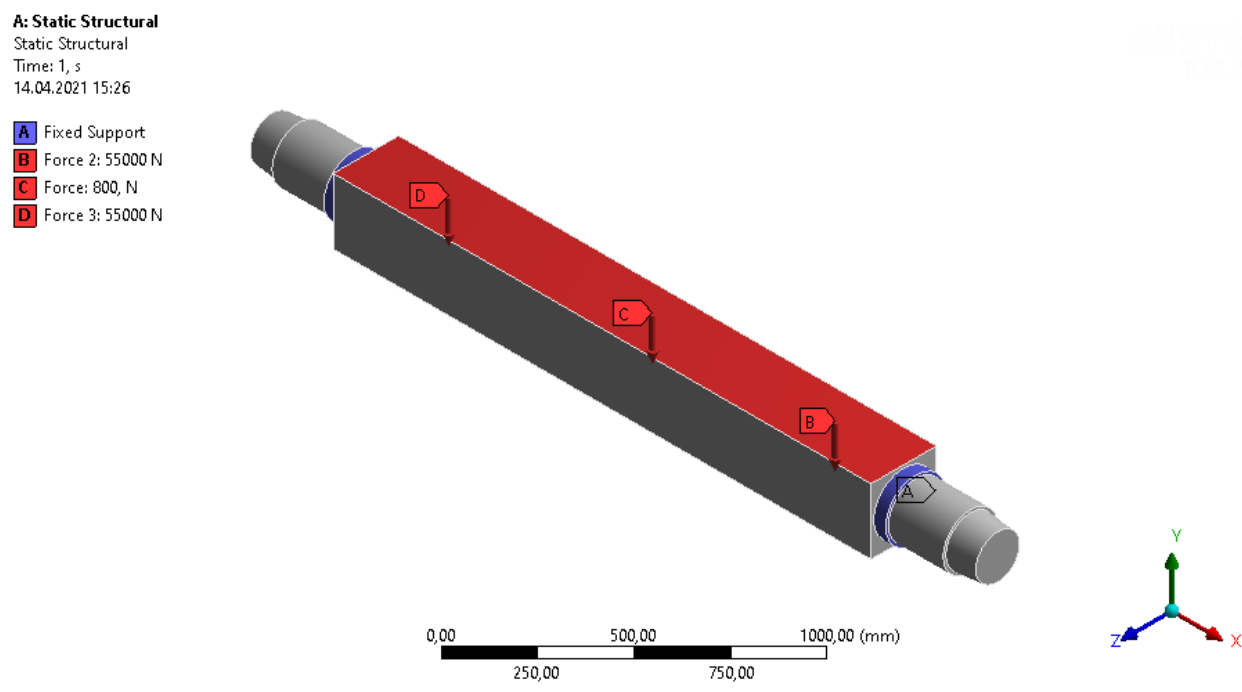

Şekil 7. Dikdörtgen kesitli tarım arabası aksının yük şeması

Figure 7. Load diagram of rectangular trailer axle.

Şekil 7'de gösterilen dikdörtgen kesitli tarım arabası aksının yük şemasında, dairesel kesitte olduğu gibi mavi renkle gösterilen A noktası sabit destek noktasıdır. Kırmızı renkle gösterilen yüzeyde ise B ve $D$ noktalarına $55000 \mathrm{~N}$ (5500 kg) yük, C noktasına ise $800 \mathrm{~N}$ (80 kg) yük uygulanmaktadır.

\section{BULGULAR}

Sonlu eleman analizi için yük diyagramında gösterildiği gibi yükler uygulanmıştır. Şekil 8'de yük uygulandığında dikdörtgen kesitli aks üzerinde oluşan eşdeğer gerilim gösterilmektedir. Kırmızı renk, maksimum gerilimi, yani $12.026 \mathrm{MPa} y ı$ ve mavi renk, aks üzerinde oluşturulan minimum gerilimi, yani $6.2856 \mathrm{e}-5 \mathrm{MPa}$ 'yı göstermektedir. 


\section{A: Static Structural}

Type: Equivalent (von-Mises) Stress

Unit: $\mathrm{MPa}$

14.04.2021 15:30
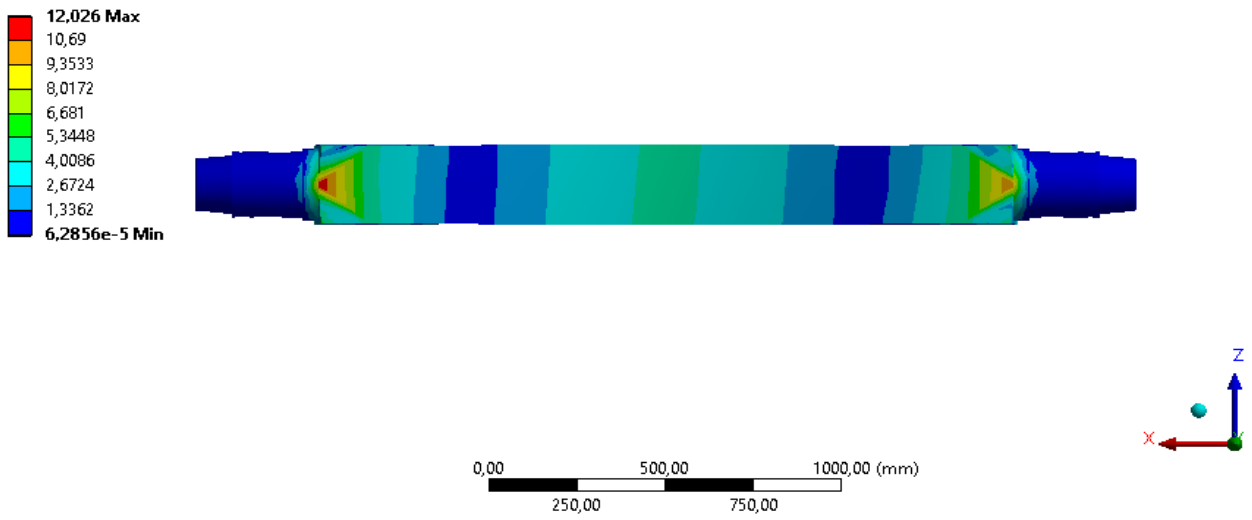

Şekil 8. Dikdörtgen kesitli aksın eşdeğer gerilimi.

Figure 8. Equivalent (von- Mises) stress of rectangular axle.

Şekil 9'da ise dairesel kesitli aks üzerinde oluşan eşdeğer gerilim gösterilmektedir. Maksimum gerilim, 15.892 $\mathrm{MPa}$ ve aks üzerinde oluşan minimum gerilim ise $4.4759 \mathrm{e}-5 \mathrm{MPa}$ bulunmuştur.
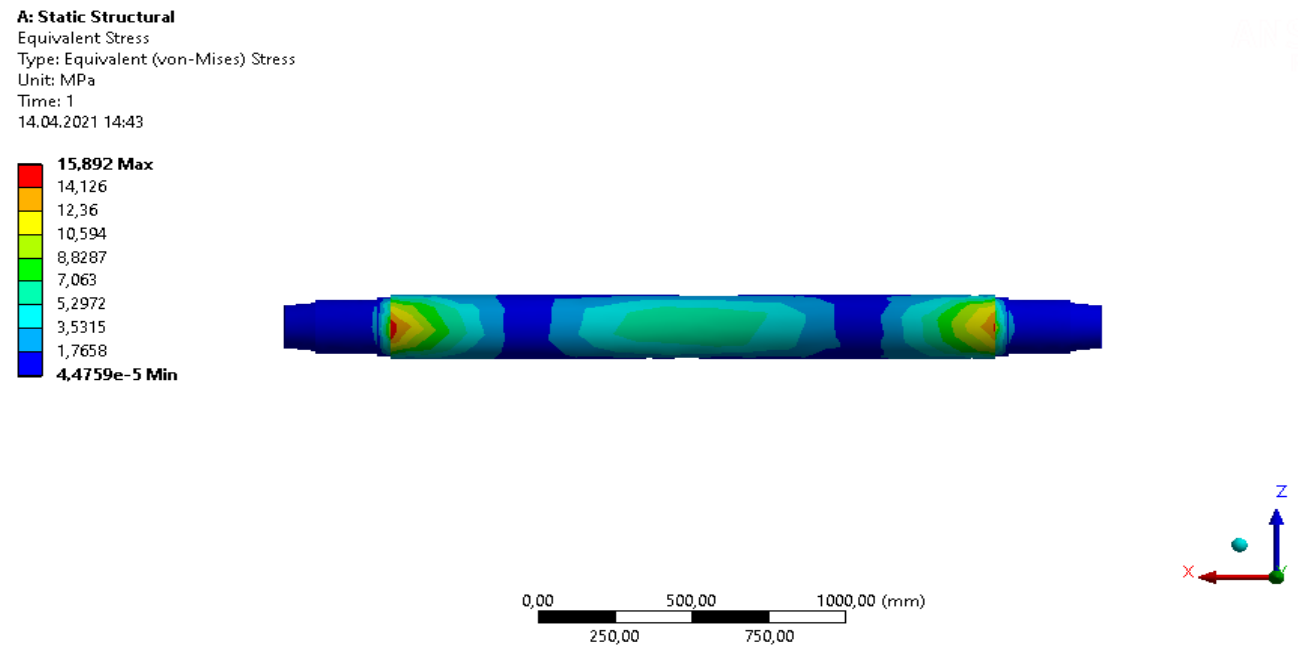

Şekil 9. Dairesel kesitli aksın eşdeğer gerilimi.

Figure 9. Equivalent (von-Mises) stress of circular axle.

Şekil $10^{\prime}$ da dikdörtgen kesitli aks üzerindeki eşdeğer elastik gerilim gösterilmektedir. Maksimum gerilim $6.8408 \mathrm{e}-5 \mathrm{~mm} \mathrm{~mm}^{-1}$ ve minimum gerilim $5.2653 \mathrm{e}-10 \mathrm{~mm} \mathrm{~mm}^{-1}$ olarak bulunmuştur.

A: Static Structural
Equivalent Elastic Stran

Equivalent Elastic Strain

Unit: $\mathrm{mm} / \mathrm{mm}$

Time: 1 14.04.2021 15:30

$6,8408 \mathrm{e}-5 \operatorname{Max}$
$6,0807 \mathrm{e}-5$

$5,3206 \mathrm{e}-5$

$4,5606 \mathrm{e}-5$

$3,8005 \mathrm{e}-5$

$3,0404 \mathrm{e}-5$

$2,2803 \mathrm{e}-5$

$1,5202 \mathrm{e}-5$

$7,6014 \mathrm{e}-6$
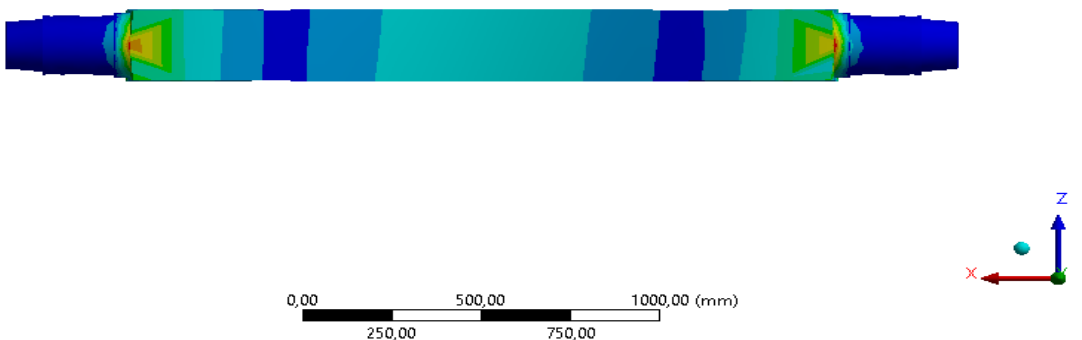

Şekil 10. Dikdörtgen kesitli aksın eşdeğer elastik gerilimi.

Figure 10. Equivalent elastic strain of rectancular axle. 
Şekil 11 'de ise dairesel kesitli aks üzerinde oluşan eşdeğer elastik gerilim gösterilmektedir. Maksimum gerilim $7.9463 \mathrm{e}-5 \mathrm{~mm} \mathrm{~mm}^{-1}$ ve aks üzerinde oluşan minimum gerilim $3.4476 \mathrm{e}-10 \mathrm{~mm} \mathrm{~mm}^{-1}$ olarak bulunmuştur.

A: Static Structural

Equivalent Elastic Strain

Type: Equivalent Elastic Strain

Unit: $\mathrm{mm} / \mathrm{mm}$

Time: 1

$14.04 .202114: 45$

$7,9463 \mathrm{e}-5 \mathrm{Max}$

$7,0634 \mathrm{e}-5$

$6,1805 e-5$

$5,2975 e-5$

$4,4146 \mathrm{e}-5$

$3,5317 \mathrm{e}-5$

$2,6488 \mathrm{e}-5$

$1,7659 \mathrm{e}-5$

$8,8295 \mathrm{e}-6$

3,4476e-10 Min
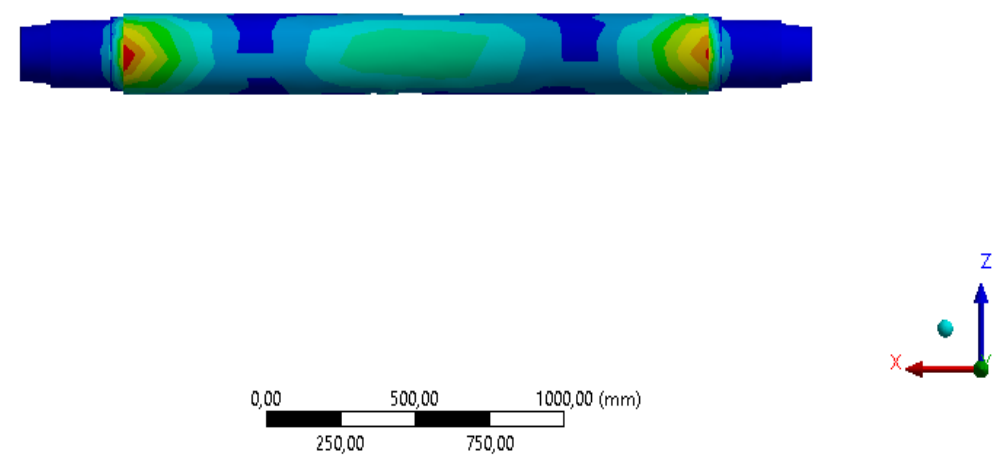

Şekil 11. Dairesel kesitli aksın eşdeğer elastik gerilimi.

Figure 11. Equivalent elastic strain of circular axle.

Şekil 12 'de yük uygulandığında dikdörtgen kesitli aks üzerindeki toplam deformasyon gösterilmektedir. Kırmızı renk, maksimum deformasyonu yani $0.053021 \mathrm{~mm}$ ve mavi renk, aks üzerinde oluşan minimum deformasyonu yani $0 \mathrm{~mm}$ göstermektedir.

\footnotetext{
A: Static Structural

Total Deformation

Type: Total Deformation

Unit: $\mathrm{mm}$

Time: 1

$14.04 .202115: 31$

\begin{tabular}{|l}
$0,053021 \mathrm{Max}$ \\
0,04713 \\
0,041239 \\
0,035348 \\
0,029456 \\
0,023565 \\
0,017674 \\
0,011783 \\
0,0058913
\end{tabular}
}
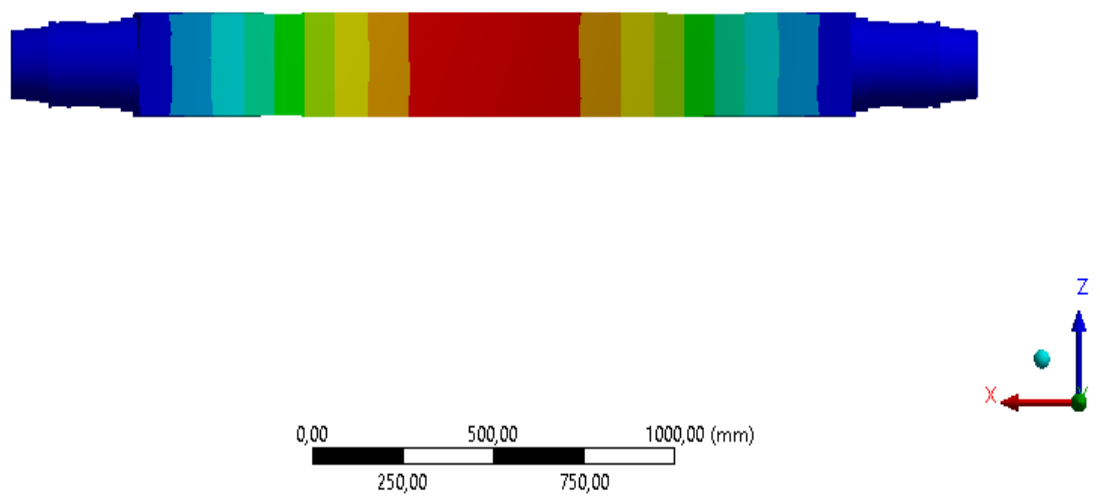

Şekil 12. Dikdörtgen kesitli aksın toplam deformasyonu.

Figure 12. Total deformation of the rectangular axle.

Dairesel kesitli aks üzerindeki maksimum deformasyon $0.077806 \mathrm{~mm}$ ve minimum deformasyon $0 \mathrm{~mm}$ bulunmuş ve Şekil 13 'te gösterilmiştir. 
14.04.2021 14:44

$0,077806 \mathrm{Max}$

0,069161

0,060516

0,06051

0,043225

0,03458

0,025935

0,01729

0,008645

0,006
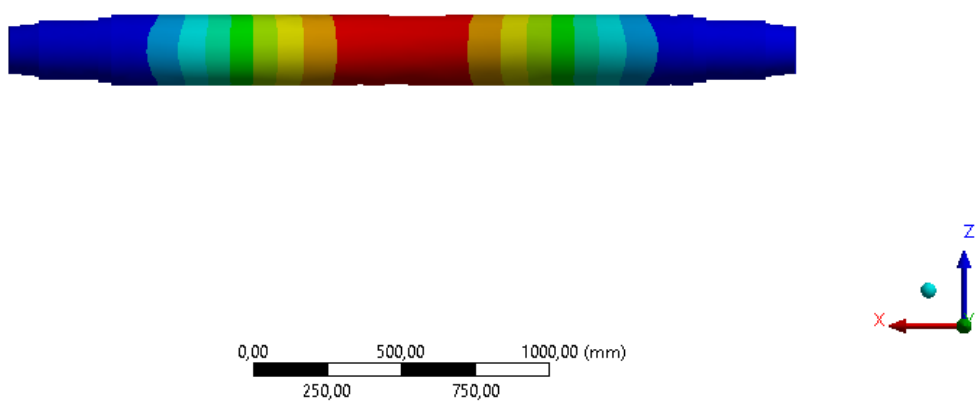

Şekil 13. Dairesel kesitli aksın toplam deformasyonu.

Figure 13. Total deformation of the circular axle.

Şekil 14 dikdörtgen kesitli aks üzerindeki güvenlik faktörünü, Şekil 15 ise daire kesitli aks üzerindeki güvenlik faktörünü göstermektedir. Mavi renk, maksimum güvenlik faktörünü ve kırmızı renk aks üzerinde oluşan minimum güvenlik faktörünü göstermektedir. Dikdörtgen kesitli aksın güvenlik faktörü maksimum ve minimum 15 bulunmuştur. Dairesel kesitli aksın güvenlik faktörü maksimum 15 ve minimum 9.9852 bulunmuştur.
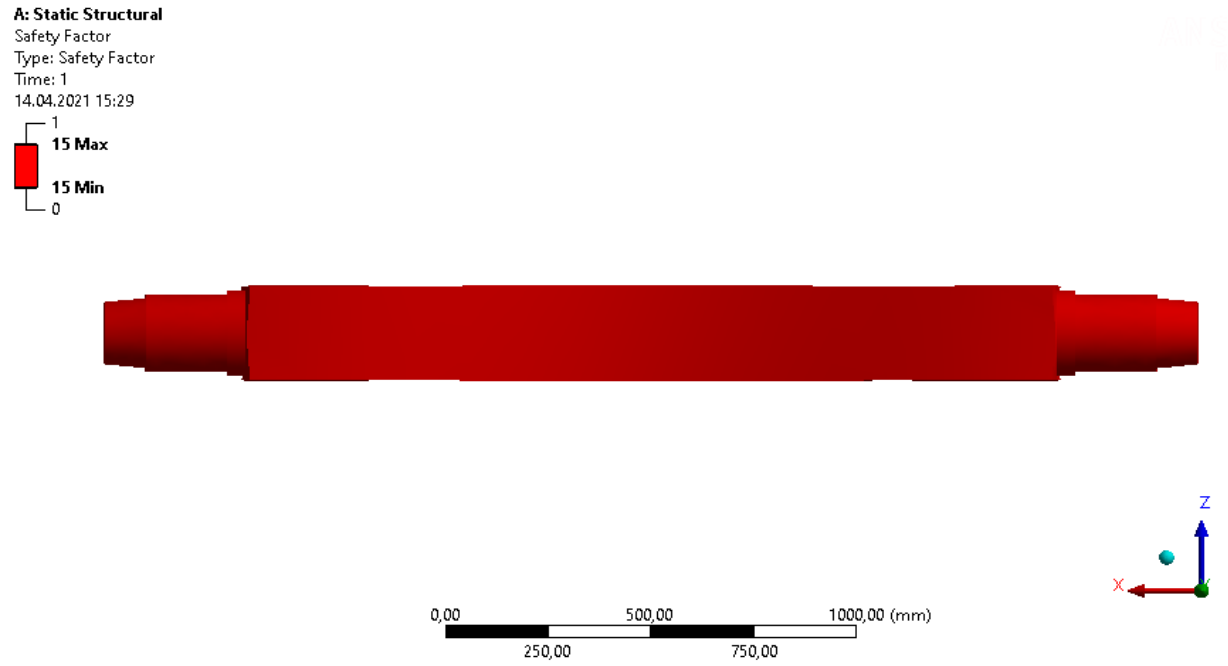

Şekil 14. Dikdörtgen kesitli aksın güvenlik faktörü.

Figure 14. Safety factor of rectangular axle.

A: Static Structural

$14.04 .202114: 46$
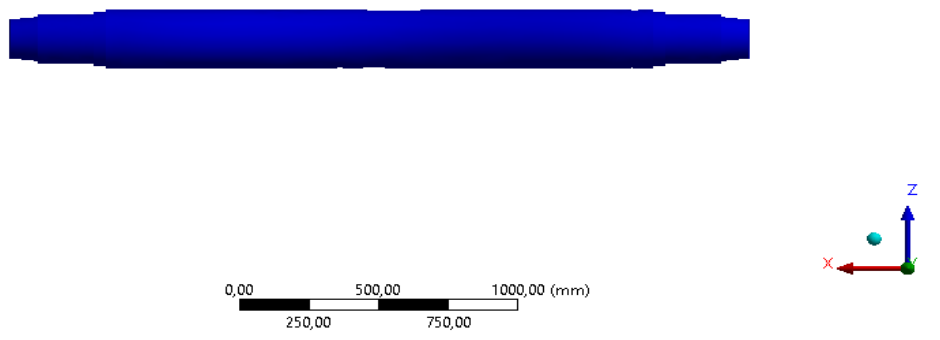

Şekil 15. Dairesel kesitli aksın güvenlik faktörü.

Figure 15. Safety factor of circular axle. 


\section{SONUÇ}

ANSYS sonlu eleman programıyla, mühendislik alanlarındaki çözümü zor ve karmaşık olan problemlerin modellenerek çok daha kolay ve kısa sürede çözüme kavuşturulması mümkündür. Her alanda olduğu gibi tarımsal alanda da ANSYS yazılım programının kullanılması hem sorunların daha kısa sürede ve ekonomik olarak çözümlenmesine hem de istenilen analizlerin pratik olarak yapılmasına imkân sağlamaktadır. ANSYS programında doğru bir modellemenin yapılmasıyla, tarımsal uygulama tasarımları gerçek ortam şartları ile test edilebilmekte ve arazide kullanımının uygunluğu daha tasarım aşamasında kolay bir şekilde tespit edilebilmektedir.

Çalışmada tarım arabası aksı analizi için yapısal çelik malzeme tercih edilmiştir. Kullanılan malzemenin yapısal özelliğinin, boyutunun ve yüklemelerinin değiştirilmesiyle farklı sonuçların ortaya çıkacağı düşünülmektedir. Örneğin (Manasa ve ark., 2013) dairesel kesitli bir aks üzerinde yaptıkları çalışmada, SAE1020 yapısal özelliğe sahip çelik malzeme kullanmışlar ve Çizelge 3'teki sonuçları elde etmişlerdir.

Çizelge 3. SAE1020 yapısal özelliğe sahip aksın gerilme analiz sonuçları (Manasa ve ark., 2013).

Table 3. Stress analysis results of axle with SAE1020 structural feature.

\begin{tabular}{lll}
\hline Adı & Maksimum & Minimum \\
\hline Eşdeğer gerilim & $99.399 \mathrm{Mpa}$ & $1.4584 \mathrm{e}-6 \mathrm{Mpa}$ \\
Elastik gerilim & $4.8487 \mathrm{e}-4$ & $7.114 \mathrm{e}-12$ \\
Toplam deformasyon & $0.55864 \mathrm{~mm}$ & 0 \\
Güvenlik faktörü & 15 & 0 \\
\hline
\end{tabular}

Tarım arabalarında kullanılan, dairesel kesitli ve dikdörtgen kesitli aksların üç boyutlu parametrik katı modellemesi yapılıp, modellenen aksların gerçek çalışma ortamlarındaki gerilme analizleri ortaya çıkarılarak karşılaştırıımıştır. Karşılaştırma yapılırken, aksların çalışma koşulları, boyutları ve yükleme miktarları eşit tutularak bu sonuçlar elde edilmiştir. Elde edilen sonuçlardan, dairesel ve dikdörtgen kesitli akslarda oluşan gerilimin izin verilen gerilimden yani $460 \mathrm{MPa}$ 'dan daha az olduğu görülmüştür. Bu sonuçlara göre, belirtilen yükleme koşulları altında tasarımın her iki aksta da güvenli olduğu ve iş esnasında herhangi bir hasara uğramadan çalışabileceği görülmektedir. Sonuçlar Çizelge 4 ve 5 'te gösterilmektedir.

Çizelge 4. Aks ağırlıkları ve izin verilen eğilme gerilimi

Table 4. Axle weights and allowable bending stress

\begin{tabular}{ll}
\hline Dikdörtgen tip aks kütlesi & $1052 \mathrm{~kg}$ \\
Dairesel tip aks kütlesi & $860.73 \mathrm{~kg}$ \\
Yapısal çeliğin izin verilen eğilme gerilimi & $460 \mathrm{MPa}$ \\
\hline
\end{tabular}

Çizelge 5. Dairesel ve dikdörtgen kesitli aksların statik analiz sonuçları.

Table 5. Static analysis results of circular and rectangular axles.

\begin{tabular}{lllll}
\hline Adı & \multicolumn{2}{c}{ Dairesel kesitli } & \multicolumn{2}{c}{ Dikdörtgen kesitli } \\
\hline & Maksimum & \multicolumn{1}{c}{ Minimum } & Maksimum & Minimum \\
\hline Eşdeğer Gerilim (MPa) & 15.892 & $4.4759 \mathrm{e}-5$ & 12.026 & $6.2856 \mathrm{e}-5$ \\
Eşdeğer Elastik Gerilim $\left(\mathrm{mm} \mathrm{mm}{ }^{-1}\right)$ & $7.9463 \mathrm{e}-5$ & $3.4476 \mathrm{e}-10$ & $6.8408 \mathrm{e}-5$ & $5.2653 \mathrm{e}-10$ \\
Toplam deformasyon $(\mathrm{mm})$ & 0.077806 & 0 & 0.053021 & 0 \\
Güvenlik faktörü & 15 & 9.9852 & 15 & 15 \\
\hline
\end{tabular}

Dairesel kesitli ve dikdörtgen kesitli aksların Çizelge $5^{\prime}$ te statik analiz sonuçları görülmektedir. Bu yüklemeler altında ortaya çıkan ve yorulma analizinde kullanılacak olan gerilmeler, dairesel kesitli aks için eşdeğer gerilim maksimum $15.892 \mathrm{MPa}$ ve minimum eşdeğer gerilim 4.4759e-5 MPa iken dikdörtgen kesitli aks için eşdeğer gerilim maksimum $12.026 \mathrm{MPa}$ ve minimum eşdeğer gerilim 6.2856e-5 MPa'dır.

Aynı durum eşdeğer elastik gerilim içinde görülmektedir. Aynı yükler altında, dairesel kesitli aksın eşdeğer elastik gerilimi maksimum 7.9463-5 mm mm${ }^{-1}$ ve minimum eşdeğer elastik gerilimi $3.4476 \mathrm{e}-10 \mathrm{~mm} \mathrm{~mm}^{-1}$ iken, dikdörtgen kesitli aksın eşdeğer elastik gerilimi maksimum $6.8408 \mathrm{e}-5 \mathrm{~mm} \mathrm{~mm}^{-1}$ ve minimum eşdeğer elastik gerilimi $5.2653 \mathrm{e}-10 \mathrm{~mm} \mathrm{~mm}^{-1}$ dir.

Toplam deformasyonlara bakıldığında ise yine aynı yükler altında dairesel kesitli aksın deformasyon oranı maksimum $0.077806 \mathrm{~mm}$ iken, dikdörtgen kesitli aksın deformasyon oranı maksimum $0.053021 \mathrm{~mm}$ 'dir. Statik analizi gerçekleştirilen akslar farkı geometrik yapıya sahip olmalarından dolayı uygulanan eşit kuvvetler altındaki 
tepki sonuçlarının farklı olduğu görülmektedir. Statik analiz sonuçlarına göre maksimum gerilmelerin asıl yükü taşıyan bölgelerde olduğu ortaya çıkmaktadır.

Mühendisliğin her alanında olduğu gibi tarımda da ANSYS programı kullanılarak, tarımsal alet ve makinelerinde istenilen analizler yapılabilir. Tarım arabaları farklı arazi koşulları ve çalışma hızlarında, farklı yükler ile yüklendiklerinden dolayı imalat aşamasında malzeme analizlerinin yapılması gerekmektedir. Bu analizlerin yapılması üreticilerin maliyet bakımından daha uygun malzeme kullanmalarına, kullanııların ise arazi şartlarına ve çalışma koşullarına uygun istenilen özellikte araç temin etmeleri bakımından önemlidir. ANSYS programında elde edilen gerilme ve yer değiştirme analizleri ile tarımsal araç ve gereçlerin istenilen özellikte olup olmadığı, üretimi yapılmadan ve gerçek şartlarda arazide kullanımına geçilmeden önce uygunluğu test edilerek tasarım ve gelişimine de katkı sağlayacağı düşünülmektedir.

\section{ÇIKAR ÇATIŞMASI}

Yazarların herhangi bir çıkar çatışması bulunmamaktadır.

\section{YAZAR KATKISI}

Birinci yazar verilerin analizi ve çalışmanın yazımı, ikinci yazar düzenleme ve kontrol, üçüncü yazar ise çizimlerin yapımına katkı sunmuştur.

\section{KAYNAKLAR}

Akdemir, S. (2016). Bir soğuk hava deposunda farklı menfez kanat açılarına göre hava dağıımının hesaplamalı akışkanlar dinamiği ile tahmini. Anadolu Tarım Bilimleri Dergisi, 31, 1308-8769.

Akman, H., Çerçi, K. N., Hürdoğan, E., \& Büyükalaca, O. (2018). Güneş enerjisi destekli bir kurutma sisteminin tasarımı, imalatı ve ilk ölçüm sonuçlarının değerlendirilmesi. Osmaniye Korkut Ata Üniversitesi Fen Bilimleri Enstitüsü Dergisi, 1(1), 1-9.

Aldağ, M. C. (2015). Tek dingilli tarım arabalarında oluşabilecek hasarların tasarım aşamasında sonlu elemanlar analiz yöntemiyle saptanması. Doktora Tezi, Fen Bilimleri Enstitüsü, Namık Kemal Üniversitesi, Tekirdağ.

Atiş, A. (2011). Hesaplamalı akışkanlar dinamiği (cfd) kullanılarak Samsun koşullarına uygun farklı sera modellerinde doğal havalandırma etkinliğinin belirlenmesi. Yüksek Lisans Tezi, Fen Bilimleri Enstitüsü, Ondokuz Mayıs Üniversitesi, Samsun.

Azade, A. (2018). Vibrational analysis and optimization of composite tractor trolley chassis using finite element analysis. International Journal of Advance Research and Innovative Ideas in Education, 4(4).

Blaabjerg, F., Lonel, D. M., Yang, Y., \& Wang, H. (2017). Renewable energy systems: technology overview and perspectives. Renewable energy devices and systems with simulations in MATLAB ${ }^{\circledR}$ and $A N S Y S^{\circledast}, 4,1-16$.

Boldea, I. G., Tutelea, L. N., Rallabandi, V., Lonel, D. M., \& Blaabjerg, F. (2017). Electric generators and their control for large wind turbines. Renewable energy devices and systems with simulations in MATLAB® ${ }^{\circledR}$ and $A N S Y S^{\circledR} .4,209-248$.

Celik, H. K., Caglayan, N., Topakci, M., Rennie, A. E. W., \& Akinci, I. (2020). Strength-based design analysis of a para-plow tillage tool. Computers and Electronics in Agriculture, 169, 105-168.

Çelik, H. K., Topakcı, M., Yılmaz, D., \& Akıncı, İ. (2007). Çizelin yapısal ve işlevsel elamanlarında sonlu elemanlar yöntemi ile mukavemet analizi. Tarım Makinaları Bilimi Dergisi, 2007, 3(2), 111-116.

Delele, M. A., Vorstermans, B., Creemers, P., Tsige, A. A., Tijskens, E., Schenk, A., \& Opara, U. L. (2012). Cfd model development and validation of a thermonebulisation fungicide fogging system for postharvest storage of fruit. Journal of Food Engineering, 108, 68.

Franco, A., Valera, D. L., Pena, A., \& Perez, A. M. (2011). Aerodynamic analysis and cfd simulation of several cellulose evaporative cooling pads used in mediterranean greenhouses. Computers and Electronics in Agriculture 76, 218-230.

Gallego, E., Rombach, G. A., Neumann, F., \& Ayuga, F. (2010). Simulations of granular flow in silos with different finite element programs: ansys vs. silo. Transactions of the American Society of Agricultural and Biological Engineers, 53(3), 819-829.

Gallego, E., Ruiz, A., \& Aguado, P. J. (2015). Simulation of silo filling and discharge using ansys and comparison with experimental data. Computers and Electronics in Agriculture 118, 281-289.

Kibar, H. (2011). Tombul fındık depolamasında tane özelliklerine bağı olarak ANSYS programılla optimum silo tasarımı. Doktora Tezi, Fen Bilimleri Enstitüsü, Ondokuz Mayıs Üniversitesi, Samsun. 
Kibar, H., \& Öztürk, T. (2012). Ansys sonlu eleman yazılımının tarımdaki uygulamaları. Iğdır Üniversitesi Fen Bilimleri Enstitüsü Dergisi, 2(2), 65-74, 2012.

Kim, K. A., Mentesidi, K., \& Yang, Y. (2017). Solar power sources: pv concentrated pv, and concentrated solar power. Renewable Energy Devices and Systems with Simulations in MATLAB ${ }^{\circledR}$ and $A N S Y S^{\circledR}, 4,17-38$.

Ma, K., Shipurkar, U., Lonel, D. M., \& Blaabjerg, F. (2017). Power electronics and controls for large wind turbines and wind farms. Renewable Energy Devices and Sistems with Simülations in MATLAB ${ }^{\circledR}$ and $A N S Y S^{\circledR}, 4,177-204$.

Manasa, P., \& Reddy, C. V. B. (2013). Modeling and analysis of tractor trolley axle using ansys. The International Organization of Scientific Research Journal of Mechanical and Civil Engineering, 6(5), 88-92.

Meng, Y., Wei, J., Wei, J., Chen, H., \& Cui, Y. (2019). An ansys/ls-dyna simulation and experimental study of circular saw blade cutting system of mulberry cutting machine. Computers and Electronics in Agriculture, 157, 38-48.

Mollazade, K., Jaferi, A., \& Ebrahimi, E. (2010). Application of dynamical analysis to choose best subsoiler's shape using ansys. New York Science Journal, 3(3).

Reddy, G. S., Narsaiah, J., \& Shashikala, G. (2017). Dynamic analysis on tillage equipment used in agriculture using ansys software. Science and Technology, 3(7).

Saravanan, R., Koti, H., \& Martin, M. R. W. (2017). Design and analysis of tractor front axle by reverse engineering approach. International Journal of Scientific Development and Research, xxxx

Selvi, K. Ç., \& Kabas, Ö. (2018). Use of solidworks in designing agricultural machines (a sample: rotary tiller). Annals of the Faculty of Engineering Hunedoara, 16(4), 101-106.

Sharma, P., \& Kumar, A. (2016). Static structural analysis and weight reduction of trolley axle using ansys. International Journal of Technical Research 5(1).

Souza, V. H. S., Dias, G. L., Santos, A. A. R., Costa, A. L. G., Santos, F. L., \& Magalhaes, L. L. (2018). Evaluation of the ınteraction between a harvester rot and a coffee branch based on finite element analysis. Computers and Electronics in Agriculture, $150,476-483$.

Şahin, A., Altuntaş, E., \& Güleç, U. (2018). Kültivatör kazayağı uç demirlerinin sonlu elemanlar metodu (sem) ile mukavemet özelliklerinin belirlenmesi. Selçuk Tarım ve Gıda Bilimleri Dergisi, 32(3), 257-265.

Terzi, İ., Özgüven, M. M., \& Altaş, Z. (2019). Tarımda modelleme ve simülasyon kullanımı. International Erciyes Agriculture, Animal \& Food Sciences Conference, Erciyes University, Kayseri/Turkey.

Thorpe, G. R. (2008). The application of computational fluid dynamics codes to simulate heat and moisture transfer in stored grains. Journal of Stored Products Research 44, 21-31.

Topakci, M., Celik, H. K., Canakci, M., Rennie, A. E. W, Akinci, I., \& Karayel, D. (2010). Deep tillage tool optimization by means of finite element method: case study for a subsoiler tine. Journal of Food, Agriculture \& Environment 8(2), 531-536.

Yu, Y., Zhang, S., Li, H., Wang, X., \& Tang, Y. (2017). Modal and harmonic response analysis of key components of ditch device based on ansys. 13th global congress on manufacturing and management, gcmm 2016. Procedia Engineering, 174, 956964. 